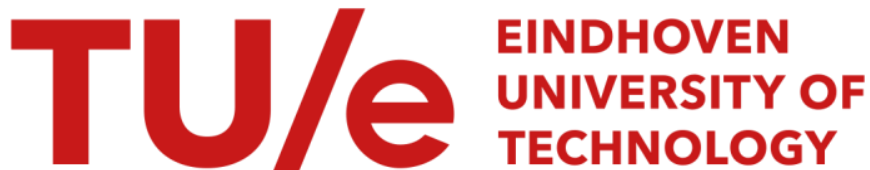

\section{Surge control of the electrically driven centrifugal compressor}

Citation for published version (APA):

Boinov, K. O., Lomonova, E. A., Vandenput, A. J. A., \& Tyagounov, A. (2006). Surge control of the electrically driven centrifugal compressor. IEEE Transactions on Industry Applications, 42(6), 1523-1531.

https://doi.org/10.1109/TIA.2006.882683

DOI:

10.1109/TIA.2006.882683

Document status and date:

Published: 01/01/2006

\section{Document Version:}

Publisher's PDF, also known as Version of Record (includes final page, issue and volume numbers)

\section{Please check the document version of this publication:}

- A submitted manuscript is the version of the article upon submission and before peer-review. There can be important differences between the submitted version and the official published version of record. People interested in the research are advised to contact the author for the final version of the publication, or visit the $\mathrm{DOI}$ to the publisher's website.

- The final author version and the galley proof are versions of the publication after peer review.

- The final published version features the final layout of the paper including the volume, issue and page numbers.

Link to publication

\section{General rights}

Copyright and moral rights for the publications made accessible in the public portal are retained by the authors and/or other copyright owners and it is a condition of accessing publications that users recognise and abide by the legal requirements associated with these rights.

- Users may download and print one copy of any publication from the public portal for the purpose of private study or research.

- You may not further distribute the material or use it for any profit-making activity or commercial gain

- You may freely distribute the URL identifying the publication in the public portal.

If the publication is distributed under the terms of Article $25 \mathrm{fa}$ of the Dutch Copyright Act, indicated by the "Taverne" license above, please follow below link for the End User Agreement:

www.tue.nl/taverne

Take down policy

If you believe that this document breaches copyright please contact us at:

openaccess@tue.nl

providing details and we will investigate your claim. 


\title{
Surge Control of the Electrically Driven Centrifugal Compressor
}

\author{
Konstantin O. Boinov, Elena A. Lomonova, Member, IEEE, \\ André J. A. Vandenput, Senior Member, IEEE, and Andrey Tyagunov
}

\begin{abstract}
This paper presents a method of the energy efficiency and the operational performance improvement of the electrically driven air compression system. The key innovation of the proposed method-the active surge suppression of the centrifugal compressor by means of the speed control of the electrical drive has been experimentally validated. This method allows the load following operation of the compression system keeping the fast response on the application demands. The described control approach is considered to be applied to the "Balance-of-Plant" of a fuel-cell power system.
\end{abstract}

Index Terms-Compressor surge control, energy efficiency, fuelcell system, high-speed induction motor, time-optimal control.

\section{INTRODUCTION}

$\mathbf{T}$ HE ELECTRICALLY driven compressors play an important role in a fuel-cell (FC) system, supplying fuel and oxidant into an FC stack. Therefore, the performance and efficiency of the whole system are directly influenced by their operation. While designing the FC generation system a number of different aspects must be taken into account-from the performance characteristics of the system components until their availability on the market. The goal of the work described in this paper was to achieve a tradeoff between the fast response and efficiency of the compression system, considering the use of the standard, reliable, and commercially available components. The innovative control solution for the electrical drive with the compressor is developed to fit their performance characteristics to the specifically demanding application-FCs.

From the FC system analysis, the desired static and dynamic performance characteristics of the auxiliary compression system have been defined. Then, a selection of the particular type of the compressor has been made in accordance to the mentioned above criteria. Finally, the matching of the performance of the compression system to the required one has been performed via the special control approach.

Paper IPCSD-06-063, presented at the 2005 Industry Applications Society Annual Meeting, Hong Kong, October 2-6, and approved for publication in the IEEE TRANSACTIONS ON INDUSTRY APPLICATIONS by the Industrial Drives Committee of the IEEE Industry Applications Society. Manuscript submitted for review October 15, 2005 and released for publication July 19, 2006.

K. O. Boinov was with the Department of Electrical Engineering, Eindhoven University of Technology, 5600 MB Eindhoven, The Netherlands. He is now with Protonic Holland BV, 1689 AL Zwaag, The Netherlands (e-mail: konstantin.boynov@protonic.nl).

E. A. Lomonova and A. J. A. Vandenput are with the Department of Electrical Engineering, Eindhoven University of Technology, $5600 \mathrm{MB}$ Eindhoven, The Netherlands (e-mail: e.lomonova@tue.nl; a.j.a.vandenput@tue.nl).

A. Tyagunov is with Apollo Systems Research Corporation, Ottawa, ON K2K 2V6, Canada (e-mail: atyagunov@ apollosrc.com).

Digital Object Identifier 10.1109/TIA.2006.882683

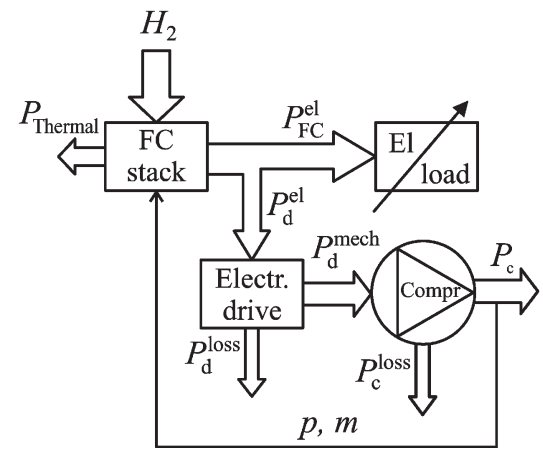

Fig. 1. FC system power flow.

The centrifugal compressors are commonly used in a wide range of air pumping applications, from combustion engine superchargers to gas distribution systems. The simple and compact mechanical design, high reliability, high efficiency, relatively high-pressure capabilities, oil-free output, and continues mass flow make this compressor one of the most attractive candidates for use in the FC systems. The FC system analysis presented further in this paper demonstrates that the main obstacle in the use of this type of compressors in the FC systems is its limited stable operation area. With the aim to overcome this constraint, a state-of-the-art active surge suppression approach has been proposed for application in the system. This control method relies on the high-performance speed control of the electrical drive and the accurate measurement and estimation of thermodynamic values, like air pressure and mass flow. The implementation of the active surge control allows to reach a tradeoff between the system efficiency and its transient characteristics achieved via the load-following control of the compression system.

\section{FC System Power Flow AND EfFiciency}

In the FC systems, the compressors are employed to supply air into the stack at a certain pressure level and a mass flow level [1]. The pressurization of the FC stack increases its power density and improves the response characteristics. On the other hand, the system efficiency is reduced due to the power consumption by the compressor subsystem [2]. The system power flow diagram is presented in Fig. 1. Produced electrical power $P_{\mathrm{FC}}^{\mathrm{el}}$ (a product of dc voltage and current) is regarded as FC output power (produced thermal power is not considered here). According to the diagram, the system efficiency $\eta_{\mathrm{FC}}^{\mathrm{E}}$ can be expressed as a ratio of the FC system output power to the 
sum of the output power and the power consumed by the drivecompressor subsystem $P_{\mathrm{d}}^{\mathrm{el}}$

$$
\eta_{\mathrm{FC}}^{\mathrm{E}}=\frac{P_{\mathrm{FC}}^{\mathrm{el}}}{P_{\mathrm{FC}}^{\mathrm{el}}+P_{\mathrm{d}}^{\mathrm{el}}} .
$$

From the FC static and dynamic models [1], [3], and [4], the requirements to the performance characteristics of the air supply equipment has been specified to provide a proper system operation. Required air supply profile has been derived using Faraday's law. In terrain conditions, the oxygen is normally taken from air. Then, considering the oxygen molar proportion in air, which equals 0.21 , and the air molecular weight $=$ $0.029 \mathrm{~kg} / \mathrm{mole}$ and taking into account the cell number $N_{\text {cell }}$, the air mass flow is defined as

$$
m=N_{\text {cell }} \frac{S_{\mathrm{O}_{2}}}{0.21} \frac{I_{\mathrm{FC}}}{4 F} 0.029
$$

where Faraday constant $F=96487 \mathrm{C} / \mathrm{mol}, I_{\mathrm{FC}}-\mathrm{FC}$ current, (A), and $S_{\mathrm{O}_{2}}$ is the oxygen stoichiometry which denotes the ratio of the inlet and consumed amount of oxygen

$$
S_{\mathrm{O}_{2}}=\frac{m_{\mathrm{O}_{2}}^{\text {in }}}{m_{\mathrm{O}_{2}}^{\text {in }}-m_{\mathrm{O}_{2}}^{\text {out }}}
$$

where $m_{\mathrm{O}_{2}}^{\text {in }}$ and $m_{\mathrm{O}_{2}}^{\text {out }}$-the inlet and outlet oxygen mass flows.

The FC air mass flow needs to be controlled rapidly and efficiently to avoid oxygen starvation and extend the lifetime of the stack [5]. Oxygen starvation occurs when the partial pressure of oxygen falls below a critical level in the FC cathode, especially at a high FC current. This phenomenon entails a rapid decrease in cell voltage, which in some cases can cause burn-through on the surface of a membrane.

This event is usually prevented either by the use of a large buffer, which allows to remove the current from the stack, or by providing the excess of oxygen stoichiometry, which normally results in the increased system complexity and extra auxiliary power consumption. Those problems could be avoided by keeping the oxygen stoichiometry at the constant level (in practice is approximately equal to two).

In this case, the operational area of the compression equipment is aimed to cover the required air mass flow levels (the correspondence of the $\mathrm{FC}$ and the compressor operation points is presented in Fig. 2). Besides, the operation of the compression equipment (and electrical drives) beyond the designed bounds results in the efficiency and stability lags (typical for centrifugal compressors) [6], [7].

Equation (1) for the system efficiency can be corrected with respect to an extension of the stable operational area of the compressor by introducing the term utilization $\kappa_{\mathrm{c}}$ of the compressor mass flow (and, respectively, its output power in case of constant pressure). It corresponds to the deviation from the constant stoichiometry. It denotes the ratio of the output power at the desired operation point to the instant one

$$
\kappa_{\mathrm{c}}=\frac{P_{\mathrm{c}}^{\text {des }}}{P_{\mathrm{c}}} \quad m^{\text {des }} \leq m\left(\text { or } \mathrm{S}_{\mathrm{O}_{2}} \geq 2\right) \quad p=\text { const }
$$

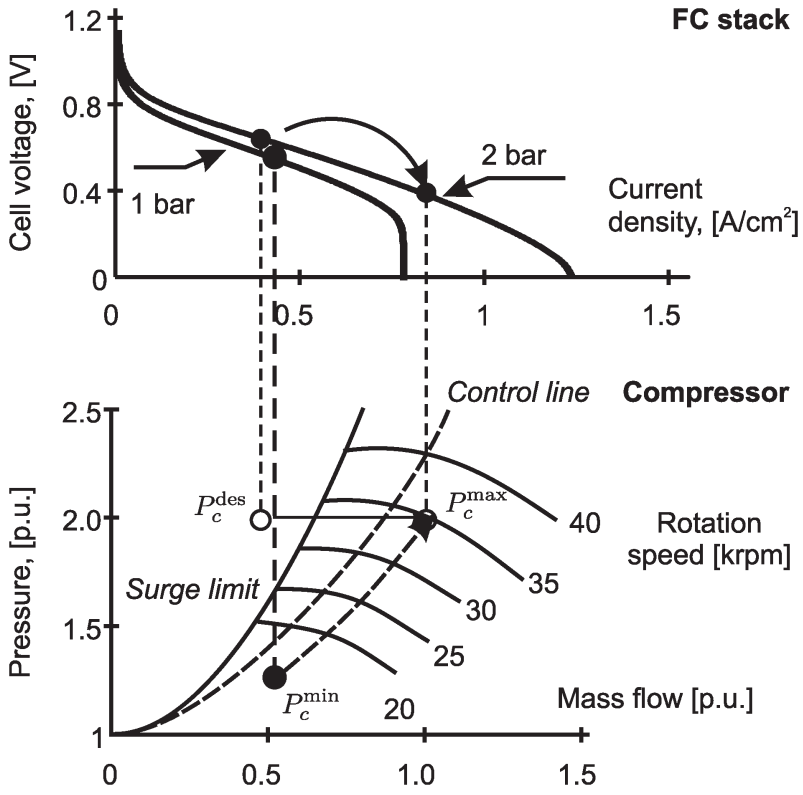

Fig. 2. FC stack and compressor operation points.

where the compressor output power $P_{\mathrm{c}}$ is

$$
P_{\mathrm{c}}=c_{\mathrm{p}} T_{01} m\left[\left(\frac{p_{2}}{p_{01}}\right)^{\frac{\gamma-1}{\gamma}}-1\right]=P_{\mathrm{d}}^{\mathrm{el}} \eta_{\mathrm{d}} \eta_{\mathrm{c}}
$$

where

$T_{01} \quad$ ambient temperature, $(\mathrm{K})$;

$p_{01}$ and $p_{2}$ ambient and outlet pressure, respectively, $(\mathrm{Pa})$;

$m \quad$ air mass flow, $(\mathrm{kg} / \mathrm{s})$;

$\gamma \quad$ ratio of specific heats, (1.4 for air);

$\eta_{\mathrm{d}}, \eta_{c} \quad$ efficiencies of the electrical drive and the compressor, respectively.

Finally, the energy efficiency of the system with FC stack, air compressor, and electrical drive is expressed as

$$
\eta_{\mathrm{FC}}^{\mathrm{E}}=\frac{\int_{t_{1}}^{t_{2}} V_{\mathrm{FC}} I_{\mathrm{FC}} d t}{\int_{t_{1}}^{t_{2}} V_{\mathrm{FC}} I_{\mathrm{FC}} d t+\int_{t_{1}}^{t_{2}} \frac{P_{\mathrm{c}}^{\mathrm{des}}}{\kappa_{\mathrm{c}} \eta_{\mathrm{d}} \eta_{\mathrm{c}}} d t}
$$

where $\left(t_{1}-t_{2}\right)$ - time interval of an operation cycle.

The derived relation allows to express the system efficiency depending on the control performance and characteristics of the compressor. Graphical representation of the obtained equations is shown in Figs. 3 and 4. The maximum of the compressor efficiency is achieved in vicinity of the surge limit. Because the energy consumption is directly proportional to the mass flow, the system efficiency reaches its maximum at the point, where the utilization equals unity.

\section{COMPRESSOR DYNAMiC MODEL AND SURGE CONTROL}

The operation area of centrifugal compressors is limited by the so-called "surge" line, which defines the stability limit in the compressor map (lower graph in Fig. 2). Traditionally, the surge has been avoided using so-called "surge avoidance" 


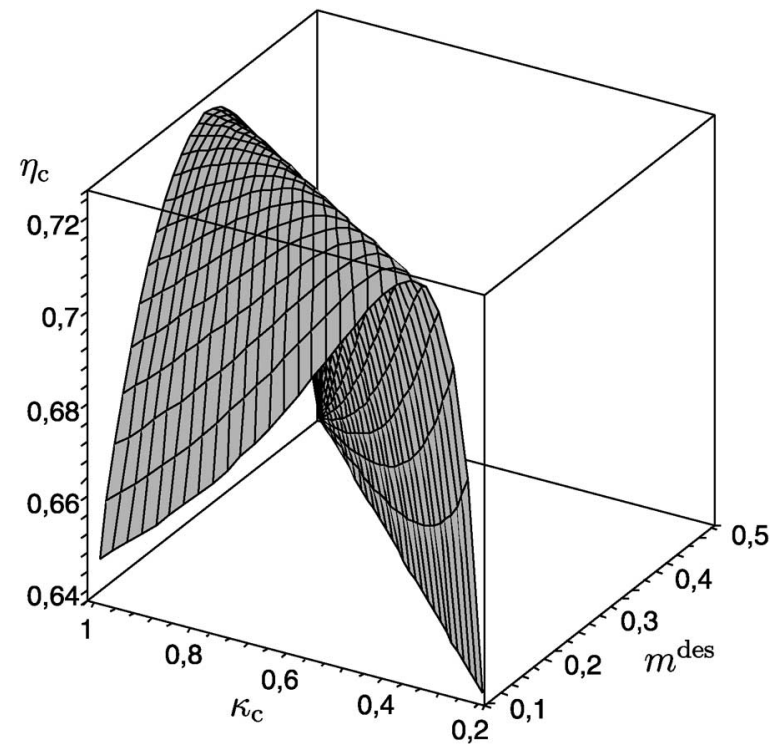

Fig. 3. Compressor efficiency $\left(\kappa_{\mathrm{c}}-m^{\text {des }}\right.$ coordinates $)$.

schemes, which restrict the efficiency and operating range of the compressor ("control line" in Fig. 2).

In the presented approach of active surge control the electrical drive is used for surge control. This means that the compressor can function at a low mass flow and high pressure without surge providing the extension of the compressor operation area.

For an extensive description of the surge phenomenon and the control development, a compressor dynamic model is used, based on the Greitzer lumped parameters model [8], [9] (Fig. 5). The dynamic model is described by the system of differential and algebraic equations

$$
\begin{aligned}
\frac{d p_{\mathrm{p}}}{d t} & =\frac{a_{0}^{2}}{V_{\mathrm{p}}}\left(m-m_{\mathrm{t}}\right) \\
\frac{d m}{d t} & =\frac{A_{1}}{L_{\mathrm{c}}}\left(\Psi_{\mathrm{c}} p_{0}-p_{\mathrm{p}}\right) \\
\frac{d \omega}{d t} & =\frac{1}{J}\left(T_{\mathrm{d}}-T_{\mathrm{c}}\right) \\
T_{\mathrm{c}} & =m \sigma \omega r_{2}^{2}
\end{aligned}
$$

where

$m_{\mathrm{t}} \quad$ mass flow through the throttle, $(\mathrm{kg} / \mathrm{s})$;

$a_{0} \quad$ inlet stagnation sonic velocity, $(\mathrm{m} / \mathrm{s})$;

$A_{1} \quad$ area of impeller eye, $\left(\mathrm{m}^{2}\right)$;

$L_{\mathrm{c}} \quad$ duct length, (m);

$J \quad$ spool moment of inertia, $\left(\mathrm{kg} \cdot \mathrm{m}^{2}\right)$;

$\omega \quad$ compressor angular speed, $(\mathrm{rad} / \mathrm{s})$;

$p_{0} \quad$ ambient pressure, $(\mathrm{Pa})$;

$p_{\mathrm{p}} \quad$ plenum pressure, $(\mathrm{Pa})$;

$V_{\mathrm{p}} \quad$ plenum volume, $\left(\mathrm{m}^{3}\right)$;

$\Psi_{\mathrm{c}} \quad$ compressor characteristics;

$T_{\mathrm{d}} \quad$ drive torque, $(\mathrm{N} \cdot \mathrm{m})$;

$T_{\mathrm{c}} \quad$ compressor torque, $(\mathrm{N} \cdot \mathrm{m})$;

$\sigma=0.9$ slip factor;

$r_{2} \quad$ external impeller radius, (m).

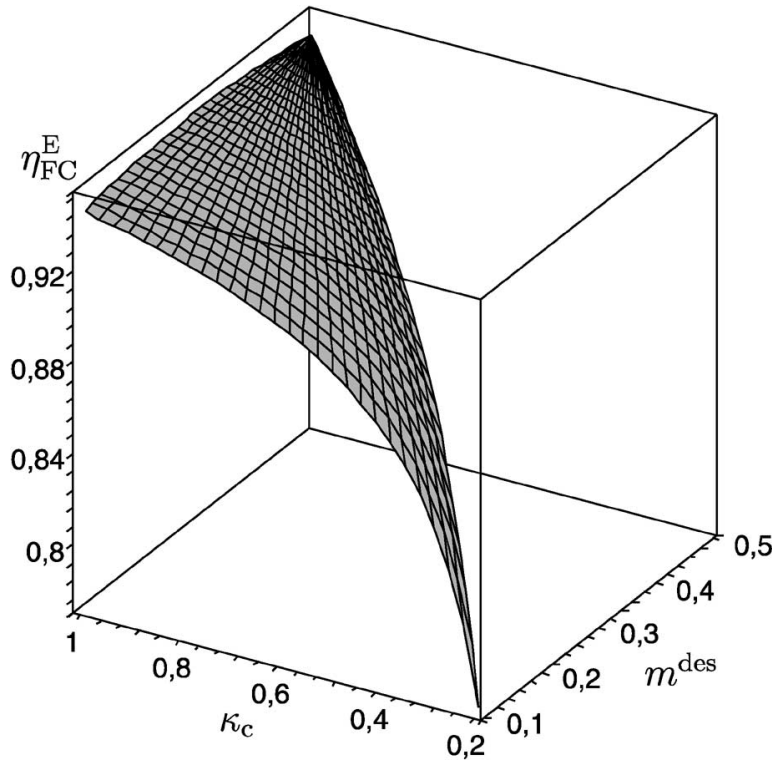

Fig. 4. System efficiency $\left(\kappa_{\mathrm{C}}-m^{\text {des }}\right.$ coordinates $)$.

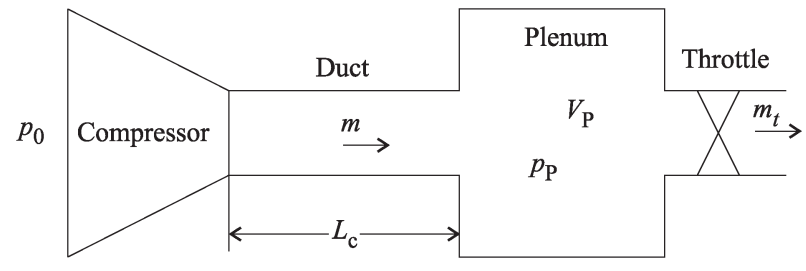

Fig. 5. Compressor, duct, plenum, and throttle system.

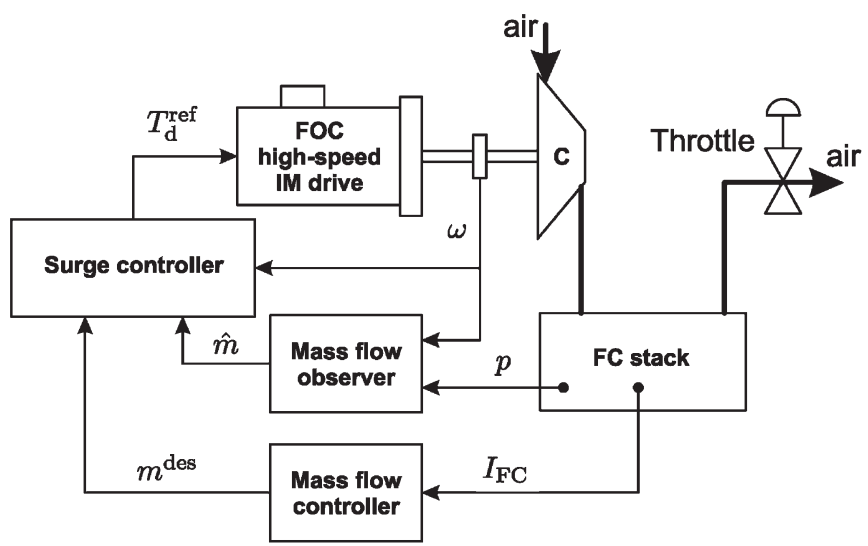

Fig. 6. Active surge control scheme.

The key feature of the active surge control is that the shaft angular speed becomes a function of the mass flow [10]

$$
\Delta \omega=-c \Delta m
$$

where $\Delta(\cdot)$ —deviation from an equilibrium, $c$ - control gain.

The mass flow and the impeller angular speed are used in this feedback control law. In fact, the reliable sensors for transient mass flow are not available (or can be rather expensive). Thus, an observer for the estimation of the mass flow has been used based on the compressor model (7)-(10). Fig. 6 represents the general compression control system with the surge controller. The model parameters used in the design are presented in Table I. 
TABLE I

COMPRESSOR MODEL PARAMETERS

\begin{tabular}{llll}
\hline$A_{1},\left(\mathrm{~m}^{2}\right)$ & $L_{\mathrm{c}},(\mathrm{m})$ & $J,\left(\mathrm{kgm}^{2}\right)$ & $V_{\mathrm{p}},\left(\mathrm{m}^{3}\right)$ \\
\hline 0.0064 & 4.4 & 0.001 & 0.028 \\
\hline
\end{tabular}

\section{INDUCTION MOTOR (IM) MODEL AND FIELD ORIENTED CONTROL}

The high-speed IM has been selected as a prime mover for the FC compressor due to its well-known advantages like simple construction, low cost, high reliability, and high efficiency. For the IM control design, the equivalent two-phase motor model has been used which represents the three-phase highspeed IM. With the additional assumptions that the stator and rotor phase windings are electrically and magnetically symmetrical, the air gap is uniform and the field distribution is sinusoidal and additionally, the effects of magnetic saturation, eddy-currents, and hysteresis are neglected, the model equations for an IM can be expressed in the synchronously rotating $d q$ frame [11]

$$
\begin{aligned}
v_{\mathrm{qs}}^{\mathrm{e}} & =R_{\mathrm{s}} i_{\mathrm{qs}}^{\mathrm{e}}+\frac{d \lambda_{\mathrm{qs}}^{\mathrm{e}}}{d t}+\omega_{\mathrm{e}} \lambda_{\mathrm{ds}}^{\mathrm{e}} \\
v_{\mathrm{ds}}^{\mathrm{e}} & =R_{\mathrm{s}} i_{\mathrm{ds}}^{\mathrm{e}}+\frac{d \lambda_{\mathrm{ds}}^{\mathrm{e}}}{d t}-\omega_{\mathrm{e}} \lambda_{\mathrm{qs}}^{\mathrm{e}} \\
0 & =R_{\mathrm{r}}^{\prime} i_{\mathrm{qr}}^{\prime \mathrm{e}}+\frac{d \lambda_{\mathrm{qr}}^{\prime \mathrm{e}}}{d t}+\left(\omega_{\mathrm{e}}-\omega_{\mathrm{r}}\right) \lambda_{\mathrm{dr}}^{\prime \mathrm{e}} \\
0 & =R_{\mathrm{r}}^{\prime} i_{\mathrm{dr}}^{\prime \mathrm{e}}+\frac{d \lambda_{\mathrm{dr}}^{\prime \mathrm{e}}}{d t}-\left(\omega_{\mathrm{e}}-\omega_{\mathrm{r}}\right) \lambda_{\mathrm{qr}}^{\prime \mathrm{e}} \\
\lambda_{\mathrm{qs}}^{\mathrm{e}} & =L_{\mathrm{ls}} i_{\mathrm{qs}}^{\mathrm{e}}+L_{m}\left(i_{\mathrm{qs}}^{\mathrm{e}}+i_{\mathrm{qr}}^{\prime \mathrm{e}}\right) \\
\lambda_{\mathrm{ds}}^{\mathrm{e}} & =L_{\mathrm{ls}} i_{\mathrm{ds}}^{\mathrm{e}}+L_{\mathrm{m}}\left(i_{\mathrm{ds}}^{\mathrm{e}}+i_{\mathrm{dr}}^{\prime \mathrm{e}}\right) \\
\lambda_{\mathrm{qr}}^{\prime \mathrm{e}} & =L_{\mathrm{lr}}^{\prime} i_{\mathrm{qr}}^{\mathrm{e}}+L_{\mathrm{m}}\left(i_{\mathrm{qs}}^{\mathrm{e}}+i_{\mathrm{qr}}^{\mathrm{e}}\right) \\
\lambda_{\mathrm{dr}}^{\prime \mathrm{e}} & =L_{\mathrm{lr}}^{\prime} i_{\mathrm{dr}}^{\mathrm{e}}+L_{\mathrm{m}}\left(i_{\mathrm{ds}}^{\mathrm{e}}+i_{\mathrm{dr}}^{\mathrm{e}}\right)
\end{aligned}
$$

where

$$
\begin{array}{ll}
R_{\mathrm{s}}, R_{r}^{\prime} & \text { stator and rotor resistances, }(\Omega) ; \\
L_{\mathrm{ls}}, L_{\mathrm{lr}}^{\prime} & \text { stator and rotor leakage inductance, }(\mathrm{H}) ; \\
L_{\mathrm{m}} & \text { magnetizing or mutual inductances, }(\mathrm{H}) ; \\
\lambda_{\mathrm{d}}^{\mathrm{e}}, \lambda_{\mathrm{qg}}^{\mathrm{e}} & d q \text {-components of stator flux linkage, }(\mathrm{Wb}) ; \\
\lambda_{\mathrm{dr}}^{\prime}, \lambda_{\mathrm{qr}}^{\prime \mathrm{e}} & d q \text {-components of rotor flux linkage, }(\mathrm{Wb}) ; \\
v_{\mathrm{ds}}^{\mathrm{e}}, v_{\mathrm{qs}}^{\mathrm{e}} & d q \text {-components of stator voltage, }(\mathrm{V}) ; \\
i_{\mathrm{ds}}^{\mathrm{e}}, i_{\mathrm{qs}}^{\mathrm{g}} & d q \text {-components of stator current, }(\mathrm{A}) ; \\
i_{\mathrm{dr}}^{\prime}, i_{\mathrm{qr}}^{\prime \mathrm{e}} & d q \text {-components of rotor current, }(\mathrm{A}) ; \\
()_{\mathrm{r}}^{\prime} & \text { rotor values referred to the stator; } \\
\omega_{\mathrm{e}}, \omega_{\mathrm{r}} & \text { electrical synchronous and rotor angular veloci- } \\
& \text { ties, }(\mathrm{rad} / \mathrm{s}) .
\end{array}
$$

The electromagnetic torque is expressed as

$$
T_{\mathrm{d}}=N_{\mathrm{p}} \frac{3}{2} \frac{L_{\mathrm{m}}}{L_{\mathrm{r}}^{\prime}}\left(i_{\mathrm{qs}}^{\mathrm{e}} \lambda_{\mathrm{dr}}^{\mathrm{e}}-i_{\mathrm{ds}}^{\mathrm{e}} \lambda_{\mathrm{qr}}^{\prime \mathrm{e}}\right)
$$

where $N_{\mathrm{p}}$ is the pole pair number.

The indirect rotor flux oriented control scheme has been implemented for the high-performance machine control. The requirement for the rotor flux orientation is that the stator current components $i_{\mathrm{ds}}^{\mathrm{e}}$ and $i_{\mathrm{qs}}^{\mathrm{e}}$ have to be in phase and quadrature with respect to the rotor flux. This can be realized by selecting a synchronously rotating $d q$-frame at speed $\omega_{\mathrm{e}}$ whose $d$-axis is

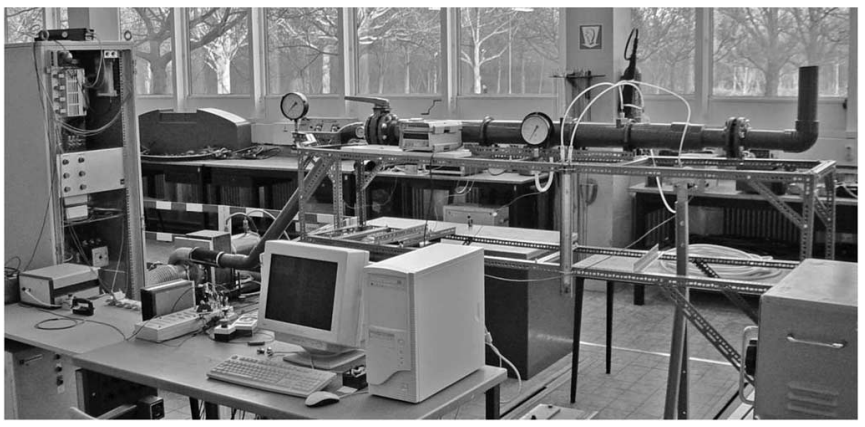

Fig. 7. Laboratory experimental setup.

TABLE II

IM PARAMETERS

\begin{tabular}{llll}
\hline Output power, $(\mathrm{kW})$ & 30 & $\begin{array}{l}\text { Equivalent circuit } \\
\text { parameters }\end{array}$ & \\
\hline Terminal voltage line-to-line, $(\mathrm{V})$ & 500 & $L_{\mathrm{m}},(\mathrm{mH})$ & 12 \\
\hline Frequency, $(\mathrm{Hz})$ & 300 & $L_{\mathrm{l}},(\mathrm{mH})$ & 0.27 \\
\hline Pole pair & 1 & $L_{\mathrm{lr}}^{\prime},(\mathrm{mH})$ & 0.27 \\
\hline Rated speed, (rpm) & 17640 & $R_{\mathrm{s}},(\mathrm{Ohm})$ & 0.07 \\
\hline Phase current, $(\mathrm{A})$ & 47 & $R_{\mathrm{r}}^{\prime},(\mathrm{Ohm})$ & 0.16 \\
\hline Over-current ratio $I_{\mathrm{a}} / I_{\mathrm{n}}$ & 6.88 & & \\
\hline Cos $(\phi)$ & 0.82 & & \\
\hline Motor efficiency, $(\%)$ & 89 & & \\
\hline
\end{tabular}

aligned with the rotor flux. This implies that the $q$-component of the rotor flux linkage $\lambda_{\mathrm{qr}}^{\mathrm{e}}$ is equal to zero: $\lambda_{\mathrm{qr}}^{\mathrm{e}}=0$. The machine is said to be rotor flux oriented.

With this method, the independent control of flux and torque is possible. By keeping the $d$-component of the rotor flux linkage $\lambda_{\mathrm{dr}}^{\prime e}$ constant it is possible to achieve a fast torque response, resulting in fast speed or position responses.

From (14), the developed electromagnetic torque can now be written as

$$
T_{\mathrm{d}}=\frac{3}{2} \frac{L_{\mathrm{m}}}{L_{\mathrm{r}}^{\prime}} N_{\mathrm{p}} \lambda_{\mathrm{dr}}^{\prime \mathrm{e}} \mathrm{e}_{\mathrm{qs}}^{\mathrm{e}}
$$

From the torque equation it can be seen that if the rotor flux linkage is not disturbed, adjusting the $q$-component of the stator current can independently control the electromagnetic torque.

\section{Active Surge Control Simulation And EXPERIMENTAL RESULTS}

The descried above active surge control of the compressor scheme has been implemented in the laboratory experimental set-up (Fig. 7) which has been installed in collaboration with the Energy Technology Group of the TU/e-Mechanical Engineering Department. The main components of the setup are: high-speed IM drive with the implemented field oriented control (FOC), power electronic converter (Semikron), centrifugal compressor (Vortech) with an embedded gearbox of ratio 1:3.45, PVC piping system, and DAQ and control systems realized on the dSpace DS1104 controller board.

The parameters of the motor (close to the needs of the FC power system compressor) are specified in Table II. The IM equivalent circuit parameters have been obtained from the 


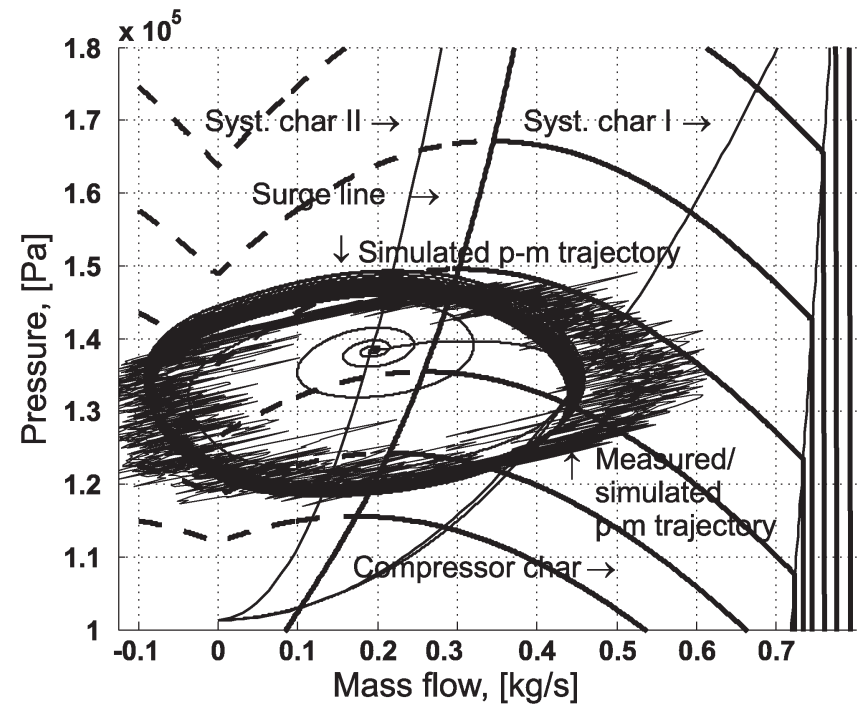

Fig. 8. Simulation and experimental results—surge.

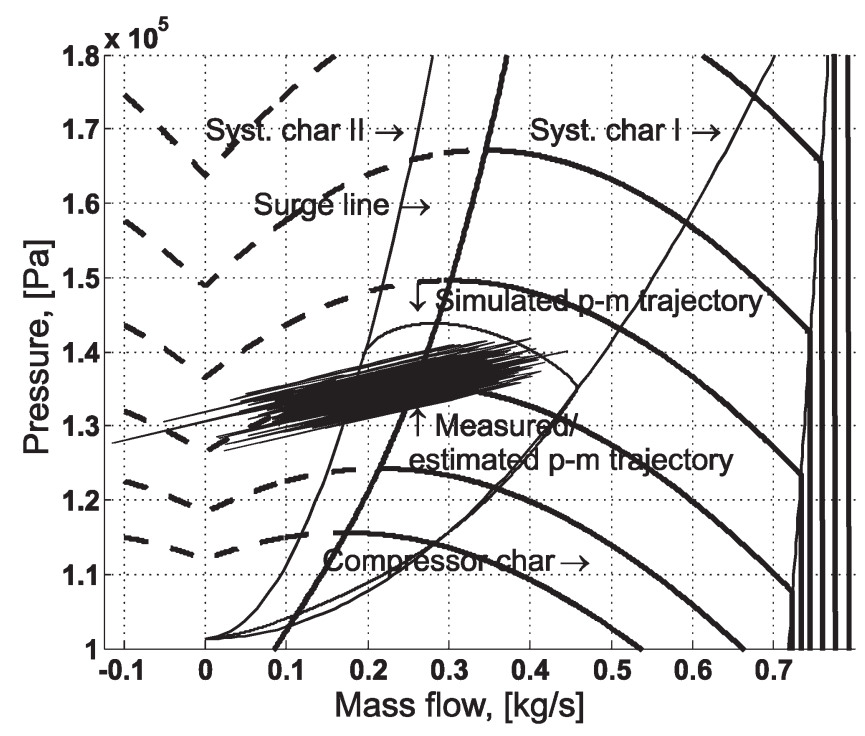

Fig. 9. Simulation and experimental results—surge control.

standard IM test [12] (dc, no-load and blocked-rotor) performed in the laboratory.

The combined simulation and experimentally obtained results of the system (7)-(9) are presented in Figs. 8 and 9. The first operating point (an intersection of the compressor and system characteristics) corresponds to the opened valve, and it is located within the stable area. When the valve is closed, the system characteristic is moved to the unstable area, where the deep surge is initialized. In case of active surge control application (11), the operation point is moved beyond the surge line but the process remains stable (Fig. 9). The effects of the surge control are shown in Fig. 10.

\section{FC System Simulation Results}

After the experimental validation of the active surge suppression method by the drive speed control, three operating regimes of the whole system with the FC stack, compressor, and IM drive have been simulated and compared (Figs. 11-16). In the

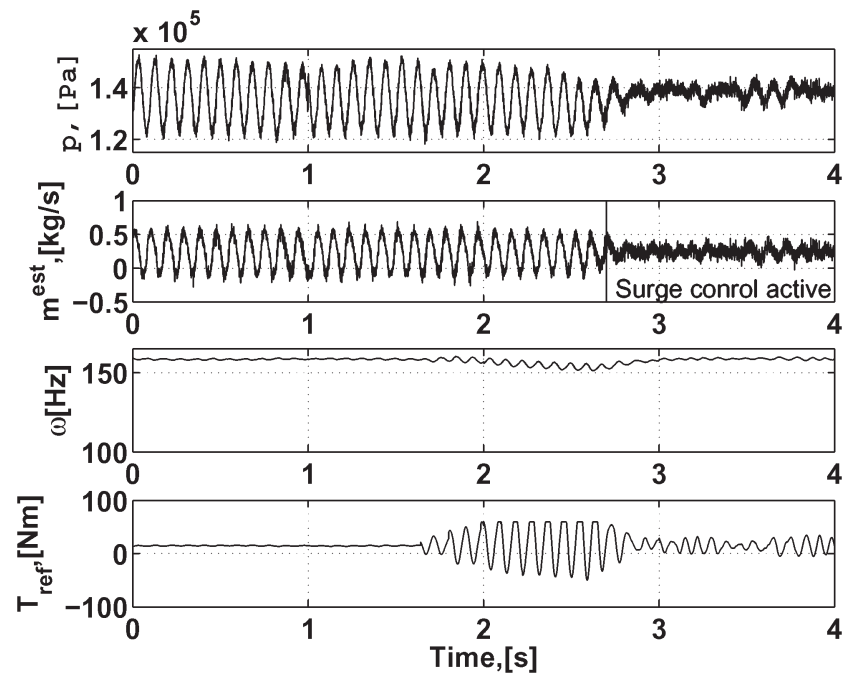

Fig. 10. Experimental results—surge control.
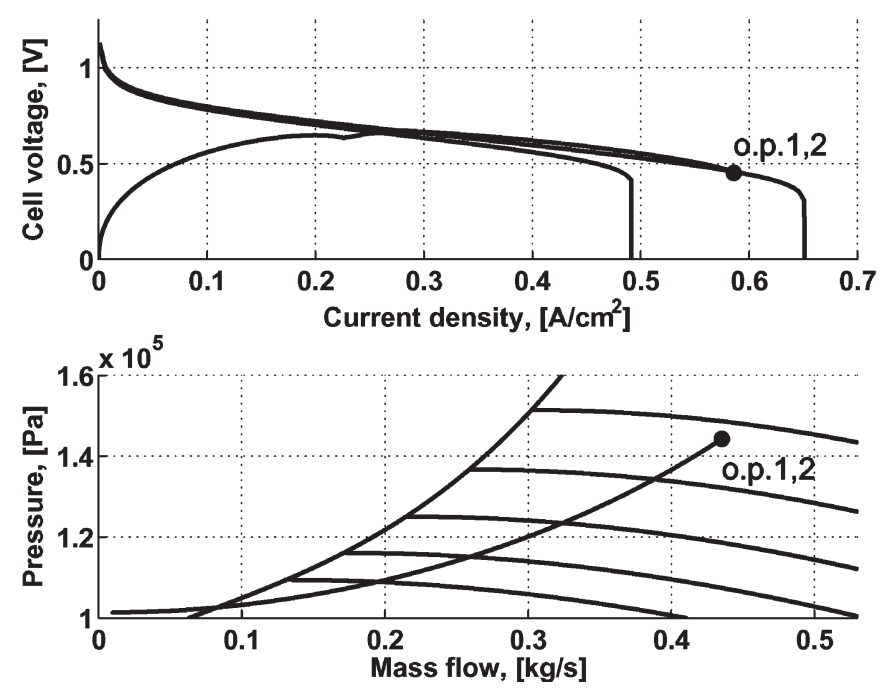

Fig. 11. FCs-compressor simulation results in state coordinates (constant speed).
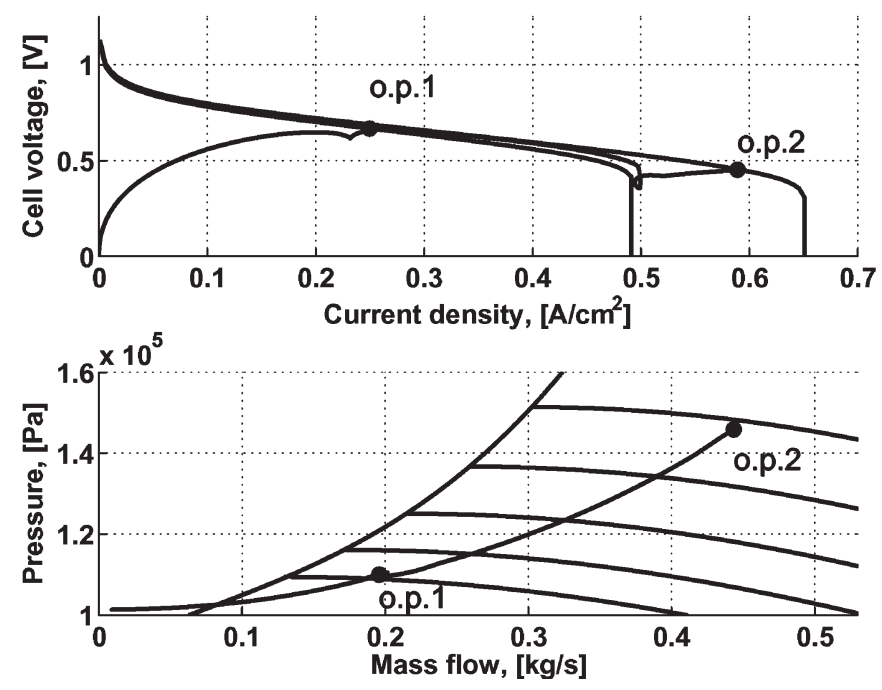

Fig. 12. FCs-compressor simulation results in state coordinates (variable speed). 

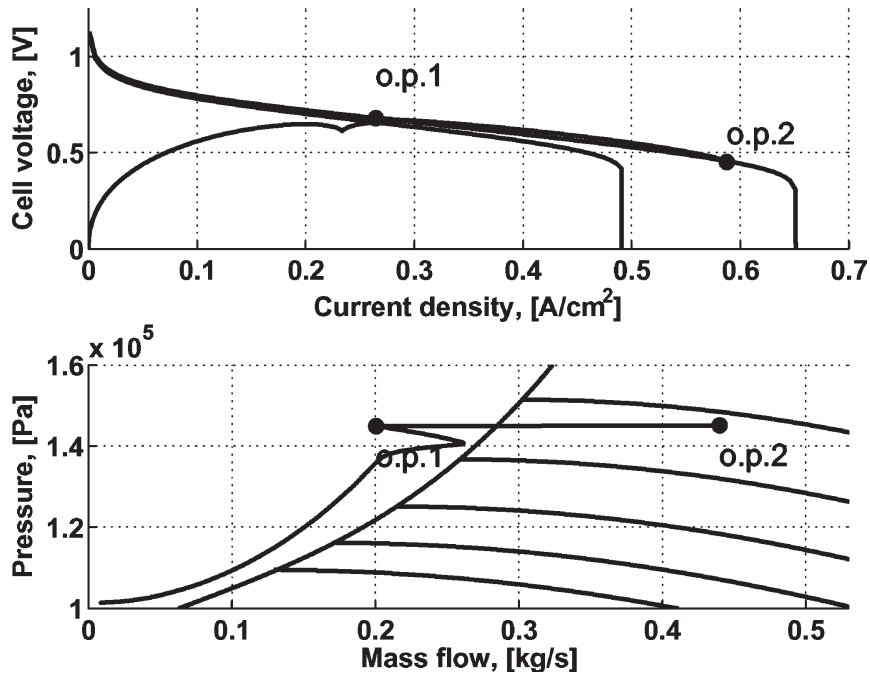

Fig. 13. FCs-compressor simulation results in state coordinates (surge control).
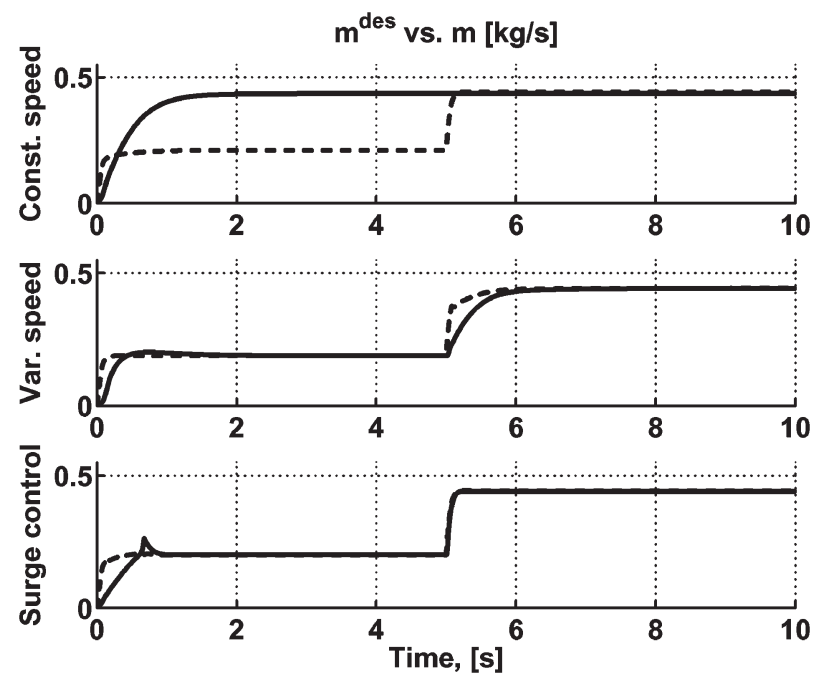

Fig. 14. Mass flow.

first regime, the compression system operates at the constant speed and constant system characteristic (valve position). The second regime corresponds to the classical variable-speed operation also at the constant valve position. In the third regime, the speed and pressure are kept approximately constant, and the only mass flow is regulated according to the FC electrical load. The developed active surge control is applied in this regime. As it can be seen from the comparison of the results, the variablespeed operation provides higher efficiency at the low FC load, due to less energy consumption by the compressor. On the other hand, the inertia of the motor rotor and the compressor impeller slows down the speed, and, consequently, the mass flow response. In Fig. 12, a visible sudden drop in the FC voltage occurs, while the system operation point moves from the low-level load (o.p.1) to the maximum (o.p.2). In this operation mode an additional energy buffer has to be installed next to the FCs to reduce the FC current and compensate that delay. This solution could be beneficial when the energy buffer is already assumed for using in the system, e.g., in systems with FCs and supercapacitors [13]. However, the use of large
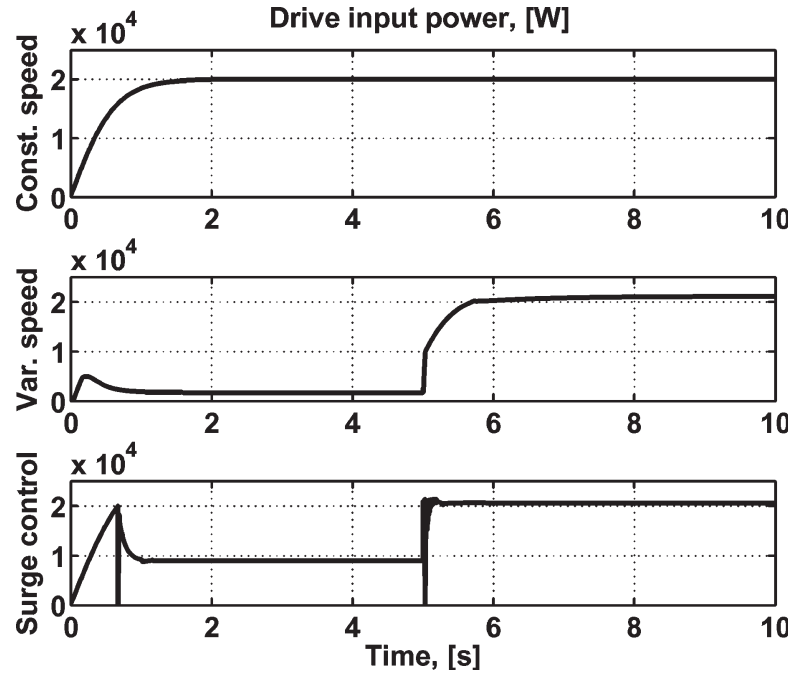

Fig. 15. Drive input power.
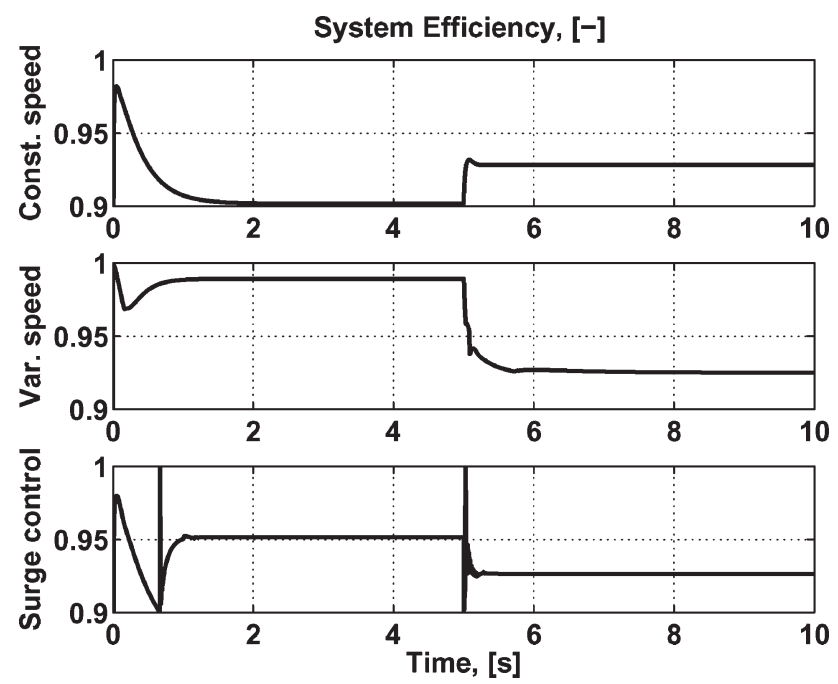

Fig. 16. System efficiency.

batteries is not always a favorite solution, especially in vehicles. The stabilization of the compressor allows to adjust the mass flow keeping very fast response. The time constant of the thermodynamic process excluding the impeller speed is defined by the geometrical parameters of the system (duct length and volume), and it is approximately one order lower, comparing to the rotor inertia.

\section{Time-Optimal Control}

The combined surge stabilization and the time-optimal control for the compression system has been developed where two inputs (the drive torque $T_{\mathrm{d}}$ and valve position $k_{\mathrm{t}}$ ) are used for the control. For the simplification of the control design, the current work deals with the linear quadratic Gaussian (LQG) problem. The LQ stands for linear systems with quadratic performance criteria. The system may be affected by disturbances and measurement noise represented as stochastic processes, in particular, by Gaussian white noise. The optimal control design methods convert control system design problems to an 


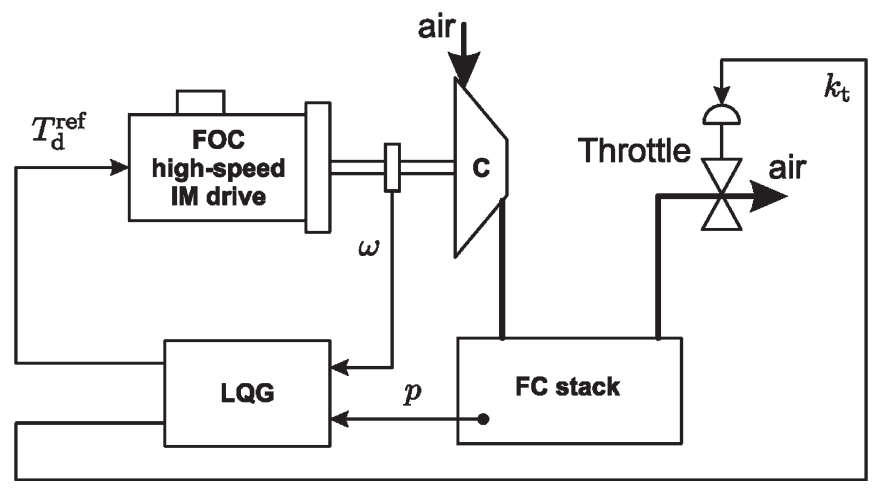

Fig. 17. LQG controller scheme.

optimization problem with time-domain performance criteria. With the LQG approach, the feedback controller (Fig. 17) coefficients are designed so that the following cost functional $J_{\mathrm{c}}$ is minimized under the "constraint" of the system dynamics $\dot{x}$

$$
\begin{aligned}
& \min _{u(t)} \quad J_{\mathrm{c}}=\frac{1}{2} \int_{0}^{\infty}\left(y(t)^{\mathrm{T}} Q y(t)+u(t)^{\mathrm{T}} R u(t)\right) d t \\
& \text { subject to } \dot{x}=f(x, u) \quad x\left(t_{0}\right)=x_{0}
\end{aligned}
$$

where

$$
x(t)=\left[\begin{array}{c}
\dot{p}_{p} \\
\dot{m} \\
\dot{\omega}
\end{array}\right] \quad u(t)=\left[\begin{array}{c}
k_{\mathrm{t}} \\
0 \\
T_{\mathrm{d}}
\end{array}\right] \quad y(t)=\left[\begin{array}{c}
p_{\mathrm{p}} \\
m \\
\omega
\end{array}\right]
$$

are state, input, and output vectors, respectively, and $Q$ and $R$ weighting matrices.

The deviation of $x$ from the reference trajectory is penalized quadratically with a nonnegative (symmetric) weighting matrix $Q$ in order to reflect different weights attached to different state components. With the choice of the weighting matrices $Q$ and $R$ a tradeoff between control performance (increasing $Q$ ) and low input energy (increasing $R$ ) can be achieved. The $Q$ and $R$ parameters have been tuned in order to obtain satisfactory behavior of the compression system. The final values of $Q$ and $R$ are: $Q=\left[10^{-12}, 1,0.02\right], R=\left[8.5 \cdot 10^{9}, 2 \cdot 10^{3}\right]$.

The linearized system around the equilibrium point is presented in the following way:

$$
\Delta x(t)=x(t)-x(t)^{0} \quad \Delta u(t)=u(t)-u(t)^{0}
$$

where $(\cdot)^{0}$ is equilibrium point and $\Delta(\cdot)$ is deviation from the equilibrium.

The state-space equation of the linearized system is, thus,

$$
\begin{aligned}
\Delta \dot{x}(t) & =A \Delta x(t)+B \Delta u(t)+G \Delta y(t) \nu(t) \\
\Delta z(t) & =C_{\mathrm{z}} \Delta x(t) \\
\Delta y(t) & =C \Delta x(t)+\varpi(t)
\end{aligned}
$$

where

$\Delta z(t) \quad$ controllable output;

$A, B, C$ state-space matrices defined from the compressor model;

$\nu(t) \quad$ plant disturbances; $\varpi(t) \quad$ measurement noise;

$C_{\mathrm{z}}$ and $G$ matrices defining controllable output and plant disturbances.

This control scheme allows to handle multiple-inputmultiple-output (MIMO) system problems almost as easily as single-input-single-output (SISO) system problems.

An optimal trajectory is generated by choosing the input for $t \geq 0$ as

$$
u(t)=-F_{\mathrm{c}} \Delta x(t) \quad F_{\mathrm{c}}=R^{-1} B^{\mathrm{T}} X
$$

where $F_{c}$ is the state feedback gain matrix, $X$ is the symmetric matrix, and the nonnegative-definite solution of the algebraic Riccati matrix equation is

$$
A^{\mathrm{T}} X+X A+C_{\mathrm{z}}^{\mathrm{T}} B C_{\mathrm{z}}-X B R^{-1} B^{\mathrm{T}} X=0 .
$$

This solution requires that the state $x(t)$ should be fully accessible for measurement. But the state $m$ of the system is not directly accessible and only the outputs $\omega$ and $p$ are measured. Thus, the reconstruction of the state $m$ is performed using an observer of the form

$$
\Delta \dot{\hat{x}}(t)=A \Delta \hat{x}(t)+B \Delta u(t)+K(\Delta y(t)-C \Delta \hat{x}(t))
$$

where

$\Delta \dot{\hat{x}}(t) \quad$ estimate $x(t)$;

$K \quad$ observer gain matrix.

The state estimate error is defined as

$e(t)=-\Delta \dot{\hat{x}}(t)=A \Delta \hat{x}(t)+B \Delta u(t)+K(\Delta y(t)-C \Delta \hat{x}(t))$.

The linearized closed-loop system is represented as

$$
\begin{array}{r}
{\left[\begin{array}{c}
\Delta \dot{x}(t) \\
\dot{e}(t)
\end{array}\right]=\left[\begin{array}{cc}
A-B F_{\mathrm{c}} & -B F_{\mathrm{c}} \\
0 & A-
\end{array}\right]\left[\begin{array}{c}
\Delta x(t) \\
e(t)
\end{array}\right]} \\
+\left[\begin{array}{c}
G v(t) \\
G v(t)+K \varpi(t)
\end{array}\right] .
\end{array}
$$

The eigenvalues of the open-loop system, the regulator, and the closed-loop system at the point, located to the left from the surge line, are presented in Fig. 18.

With this method, the different operation regimes can be realized, depending on the desired system requirements. The example of the improved variable-speed operation along the time-optimal trajectories is presented in Figs. 19 and 20.

\section{CONCLUSION}

This paper describes two innovative operation regimes of the electrically driven centrifugal compressor for FC applications. The main goal of these control methods is the improvement of the system efficiency during the reduced FC electrical load keeping the fast response on the FC demand. The proposed methods are based on the active surge suppression of the centrifugal compressor, which has been experimentally verified. Four operation regimes have been compared.

The constant-speed operating mode results in the fastest response, since there are no transients in the compression system. 


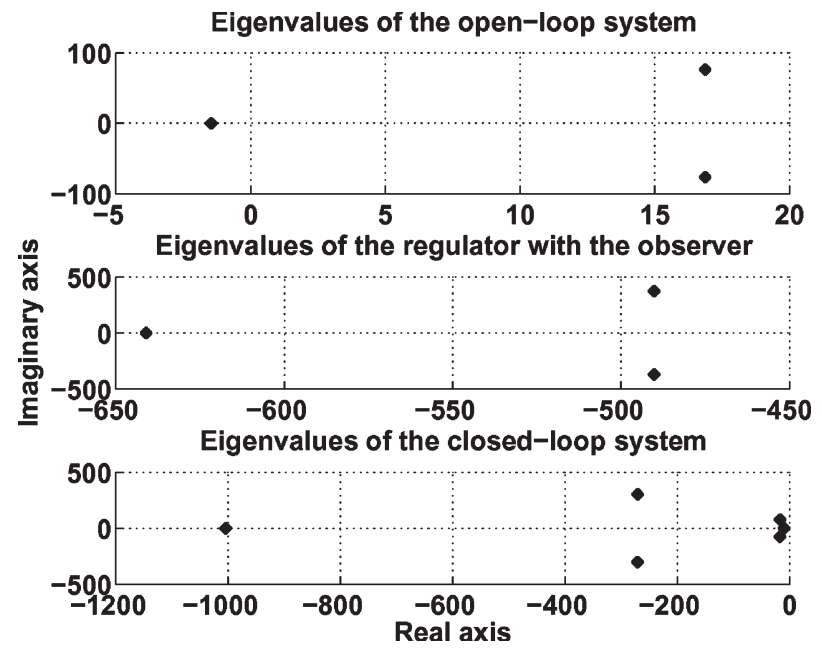

Fig. 18. System eigenvalues.
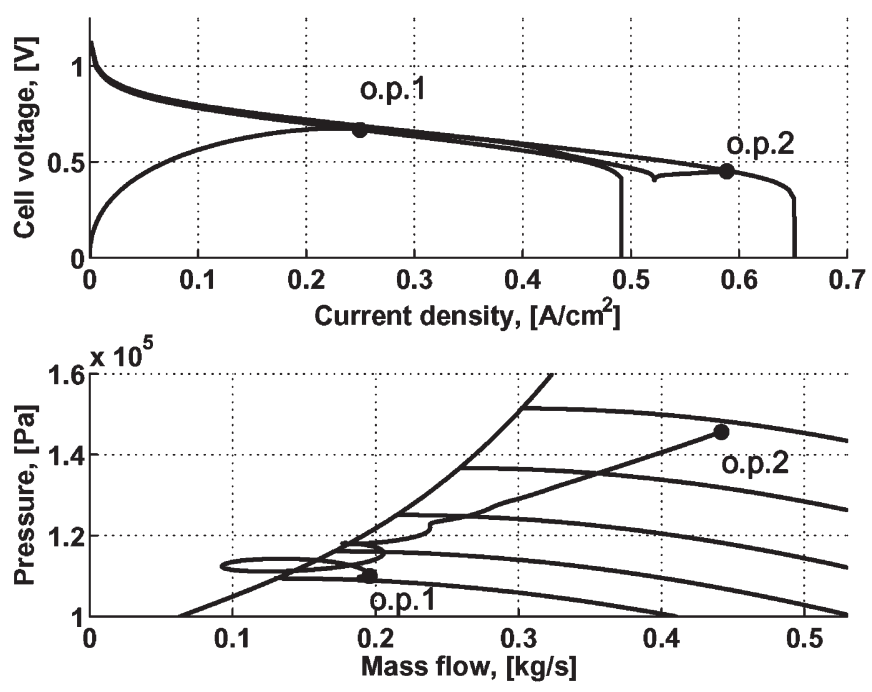

Fig. 19. FC—compressor simulation results (LQG control).

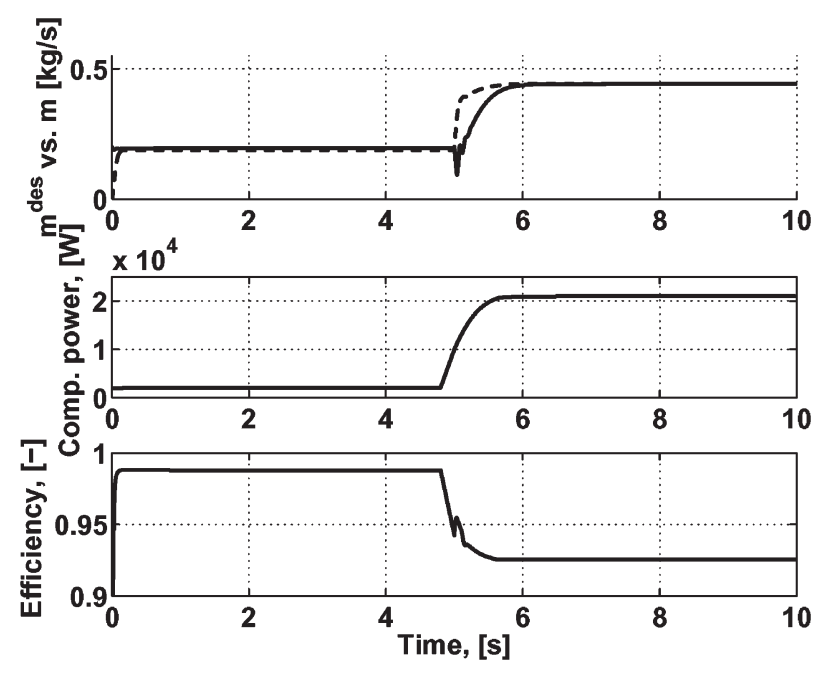

Fig. 20. LQG control simulation results.

However, system efficiency is reduced due to the extra power consumption by the compressor.

In the classical variable-speed operation mode, the compressor also works entirely in the stable area, and it results in the highest efficiency gain at the reduced load. Meanwhile, it causes the significant delay in the response due to the mechanical transient.

The tradeoff between efficiency and response time has been achieved while the active surge control is applied. The transient time is reduced by approximately $90 \%$ in comparison to the variable speed mode, but at cost of $4 \%$ efficiency. However, this method exhibits 5\% higher efficiency, than the constant speed mode.

The time-optimal MIMO LQG controller has been proposed as the extension of the surge suppression scheme and variable speed operation. It provides the transition between the operating points along the time-optimal trajectories. As it was demonstrated, about $25 \%$ reduction of the transient time can be achieved comparing to the variable speed mode while keeping the same efficiency.

\section{REFERENCES}

[1] J. Larminie and A. Dicks, Fuel Cell Systems Explained. Hoboken, NJ: Wiley, 2000.

[2] D. Thirumalai and R. White, "Steady-state operation of a compressor for a proton exchange membrane fuel cell system," J. Appl. Electrochem., vol. 30, no. 5, pp. 551-559, May 2000.

[3] J. C. Amphlett, R. M. Baumert, R. F. Mann, B. A. Peppley, and P. R. Roberge, "Performance modeling of the Ballard Mark IV solid polymer fuel cell," J. Electrochem. Soc., vol. 142, no. 1, pp. 1-15, Jan. 1995.

[4] R. F. Mann, J. C. Amphlett, M. A. I. Hooper, H. M. Jensen, B. A. Peppley, and P. R. Roberge, "Development and application of a generalized steadystate electrochemical model for a PEM fuel cell," J. Power Sources, vol. 86, no. 1/2, pp. 173-180, Mar. 2000.

[5] J. Pukrushpan, A. Stefanopoulou, and H. Peng, "Control of fuel cell breathing," IEEE Control Syst. Mag., vol. 24, no. 2, pp. 30-46, Apr. 2004.

[6] F. Willems, "Modeling and Bounded Feedback Stabilization of Centrifugal Compressor Surge," Ph.D. dissertation, Technische Universiteit Eindhoven, Eindhoven, The Netherlands, 2000.

[7] D. Fink, N. Cumpsty, and E. Greitzer, "Surge dynamics in a free-spool centrifugal compressor system," Trans. ASME, J. Turbomach., vol. 114, pp. 321-332, 1992.

[8] E. Greitzer, "Surge and rotating stall in axial flow compressors, Part I: Theoretical compression system model," J. Eng. Power, vol. 98, no. 2, pp. 190-217, 1976.

[9] J. T. Gravdahl and O. Egelan, "A Moore-Greitzer axial compressor model with spool dynamics," in Proc. 36th IEEE Conf. Decis. and Control, San Diego, CA, Dec. 1997, pp. 4714-4719.

[10] J. Gravdahl, O. Egeland, and S. Vatland, "Active surge control of centrifugal compressors using drive torque," Automatica, vol. 38, no. 11, pp. 1881-1893, 2002.

[11] D. W. Novotny and T. A. Lipo, Vector Control and Dynamics of AC Drives. Oxford, U.K.: Clarendon, 1996.

[12] IEEE Standard Test Procedure for Polyphase Induction Motors and Generators. IEEE Std. 112-1996.

[13] A. Kotsopoulos, J. Duarte, and M. Hendrix, "A converter to interface ultracapacitor energy storage to a fuel cell system normally operating with batteries," in Proc. IEEE ISIE, 2004, pp. 827-832.

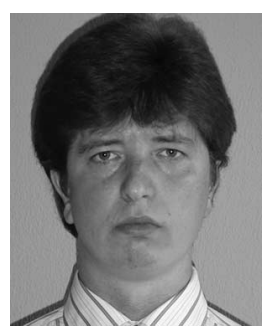

Konstantin O. Boinov received the M.Sc. degree in electromechanical engineering from Moscow State Aviation Institute (TU), Moscow, Russia, in 1999.

From 2001 to 2005, he was a Ph.D. student at Eindhoven University of Technology, The Netherlands. Currently, he is with Protonic Holland, BV, Zwaag, The Netherlands. His research interests include system analysis, mathematical modeling, and design of electromechanical and control systems. 


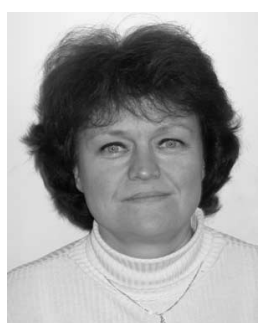

Elena A. Lomonova (M'04) was born in Moscow, Russia. She received the M.Sc. (cum laude) and $\mathrm{Ph} . \mathrm{D}$. (cum laude) degrees in electromechanical engineering from Moscow State Aviation Institute (TU), Moscow, Russia, in 1982 and 1993, respectively.

She is currently an Assistant Professor at Eindhoven University of Technology, Eindhoven, The Netherlands. She has worked on electromechanical actuators design, optimization, and development of advanced mechatronics systems.

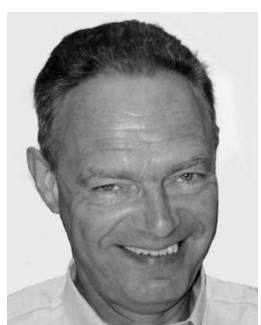

André J. A. Vandenput (M'77-SM'87) received the Ph.D. degree from the Catholic University of Leuven, Leuven, Belgium, in 1977.

From 1973 to 1991 , he was with the Laboratory for Electrical Machines and Drives, Catholic University of Leuven, first as Researcher of the Belgian National Fund for Scientific Research and since 1987 as a Professor. He was a Visiting Professor with the University of Colorado, Boulder, from 1983 to 1984, and a Research Fellow of the Japan Society for Promotion of Science with the University of Tokyo, Tokyo, Japan, in 1986. Since 1991, he has been a full time Professor and Chairman of the Electromechanics and Power Electronics Section, Eindhoven University of Technology, Eindhoven, The Netherlands. His teaching and research interests include high-performance electric drives, including electrical machines, power electronics, and control techniques.

Dr. Vandenput received the Alexander von Humboldt-Stipendium for performing research at the Rheinisch-Westfälische Technische Hochschule, Aachen, Germany, between 1980 and 1981.

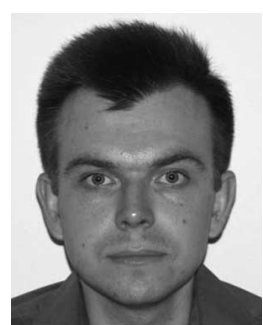

Andrey Tyagunov received the M.Sc. and Ph.D. degrees in electrical engineering from Eindhoven University of Technology, Eindhoven, The Netherlands, in 2000 and 2004, respectively.

He was an Electronics Design Engineer at Philips Lighting Electronics, Eindhoven, until 2006 with core involvement in signal processing and digital control technology projects for power electronics. Currently, he is with Apollo Systems Research Corporation, Ottawa, ON, Canada. His research interests include mathematical modeling, system analysis, control systems design, and signal processing. 